Review

\title{
A fork in the path
}

\section{Developing therapeutic inroads with FoxO proteins}

\author{
Kenneth Maiese, ${ }^{1-5, *}$ Jinling Hou, ${ }^{1}$ Zhao Zhong Chong ${ }^{1}$ and Yan Chen Shang ${ }^{1}$ \\ 'Division of Cellular and Molecular Cerebral Ischemia; ${ }^{2}$ Departments of Neurology and Anatomy \& Cell Biology; ${ }^{3}$ Barbara Ann Karmanos Cancer Institute; ${ }^{4}$ Center for \\ Molecular Medicine and Genetics; ${ }^{5}$ Institute of Environmental Health Sciences; Wayne State University School of Medicine; Detroit, MI USA
}

Key words: aging, angiogenesis, apoptosis, cancer, diabetes, immune system, ischemia, neurodegeneration, oxidative stress, stem cells

Advances in clinical care for disorders involving any system of the body necessitates novel therapeutic strategies that can focus upon the modulation of cellular proliferation, metabolism, inflammation and longevity. In this respect, members of the mammalian forkhead transcription factors of the $\mathrm{O}$ class (FoxOs) that include FoxO1, FoxO3, FoxO4 and FoxO6 are increasingly being recognized as exciting prospects for multiple disorders. These transcription factors govern development, proliferation, survival and longevity during multiple cellular environments that can involve oxidative stress. Furthermore, these transcription factors are closely integrated with several novel signal transduction pathways, such as erythropoietin and Wnt proteins, that may influence the ability of FoxOs to act as a "double-edge sword" to sometimes promote cell survival, but at other times lead to cell injury. Here we discuss the fascinating but complex role of FoxOs during cellular injury and oxidative stress, progenitor cell development, fertility, angiogenesis, cardiovascular function, cellular metabolism and diabetes, cell longevity, immune surveillance and cancer.

\section{Introduction}

Members of the mammalian forkhead transcription factors of the $\mathrm{O}$ class (FoxOs) that include FoxO1, FoxO3, FoxO4 and FoxO6 are found throughout the body and are expressed in tissues of the reproductive system of males and females, skeletal muscle, the cardiovascular system, lung, liver, pancreas, spleen, thymus and the nervous system. ${ }^{1-6}$ Since FoxO proteins are not equally expressed in all tissues, it is possible that individual FoxO proteins may have specificity in regards to cellular function. ${ }^{7}$ For example, FoxO6 expression is found in several regions of the brain that

\footnotetext{
${ }^{*}$ Correspondence to: Kenneth Maiese; Department of Neurology; 8C-1 UHC; Wayne State University School of Medicine; 4201 St. Antoine; Detroit, Ml 48201 USA; Fax: 313.966.0486; Email: kmaiese@med.wayne.edu / aa2088@wayne. edu

Submitted: 04/06/09; Revised: 04/23/09; Accepted: 04/27/09

Previously published online as an Oxidative Medicine and Cellular Longevity E-publication:

http://www.landesbioscience.com/journals/oximed/article/8916
}

play a significant role in cognitive function and emotion, such as the hippocampus, the amygdala and the nucleus accumbens. ${ }^{4}$ In contrast, FoxO1 may be more suited for the control of motor function and memory formation, since the expression of this protein is primarily in the striatum and sub-regions of the hippocampus. ${ }^{4}$ In addition, FoxO3 is more diffusely represented in the hippocampus, cortex and cerebellum, suggesting a complementary role for this FoxO protein to control cognitive and motor function. FoxO expression can be variable in other tissues. Although studies in mice have shown that the mRNA distribution of Foxo1, Foxo3a and Foxo4 is similar in the embryo and adult, ${ }^{2}$ Foxo 1 expression was highest in adipose tissue, Foxo3a expression was greatest in the liver, and Foxo 4 expression was strongest in muscle. ${ }^{2}$ Subsequent work in mice has described Foxol expression in all tissues with high levels in the ovaries. ${ }^{8}$ Foxo3a also was found to be expressed in all tissues and Foxo4 expression was considered to be more tissue specific in skeletal muscle. ${ }^{8}$

Over 100 forkhead genes and 19 human subgroups that range from FOXA to FOXS are now known to exist since the initial discovery of the fly Drosophila melanogaster gene forkhead. ${ }^{9}$ The prior nomenclature for these proteins, such as forkhead in rhabdomyosarcoma $(F K H R)$, the Drosophila gene fork head $(f k h)$, and Forkhead RElated ACtivator (FREAC)-1 and -2, has been replaced. The current nomenclature for human Fox proteins places all letters in uppercase, otherwise only the initial letter is listed as uppercase for the mouse, and for all other chordates the initial and subclass letters are in uppercase. ${ }^{10}$ Initially, the FoxOs were first reported in fusion genes in human soft-tissue tumors and leukemias. FOXO1, termed forkhead in rhabdomyosarcoma (FKHR), and FOXO3a, also known as FKHRL1 (forkhead in rhabdomyosarcoma like protein 1), and their genes were identified through chromosomal translocations in alveolar rhabdomyosarcoma tumors. ${ }^{11}$ The acute leukemia fusion gene located in chromosome $\mathrm{X}(A F X)$, also known as the FOXO4 gene, was described as a gene that fused to MLL transcription factor as a result of the $t(X ; 11)$ chromosomal translocation in acute lymphoblastic leukemia. ${ }^{12} \mathrm{~A}$ fusion between FOXO2 and MLL also occurs in some cases of acute myeloid leukemia that also is believed to be identical to FOXO3a. ${ }^{13}$

FoxO proteins function as transcription factors to either inhibit or activate target gene expression. ${ }^{14}$ As a result, these proteins must 
bind to DNA through the forkhead domain that relies upon fourteen protein-DNA contacts. The forkhead domain in Fox proteins consists of three $\alpha$-helices, three $\beta$-sheets and two loops that are referred to as the wings, ${ }^{15}$ but not all winged helix domains are considered to be Fox proteins. ${ }^{16}$ On X-ray crystallography ${ }^{15}$ or nuclear magnetic resonance imaging, ${ }^{17}$ the forkhead domain is described as a "winged helix" as a result of a butterfly-like appearance. High sequence homology is present in the $\alpha$-helices and $\beta$-sheets with variations described in either absent $\beta$-sheets and loops or additional $\alpha$-helices. Although both the first and second loops make contact with DNA, it is the second loop that can influence the stability of DNA binding. In addition, post-translational modification of FoxO proteins, such as phosphorylation or acetylation that block FoxO activity, alter the binding of the C-terminal basic region to DNA to prevent transcriptional activity. ${ }^{18}$ However, other mechanisms may influence DNA binding of forkhead proteins, such as variations in the $\mathrm{N}$-terminal region of the DNA recognition helix, changes in electrostatic distribution and the ability of forkhead proteins to be shuttled to the cell nucleus. 5,19

\section{Fox0 Proteins, Oxidative Stress and Cell Injury}

Cellular injury that leads to apoptosis can become a significant component for pathology in diseases such as neurodegenerative disease, diabetes mellitus (DM) and cardiovascular injury. ${ }^{20}$ More importantly, regulation of apoptotic pathways appears to serve a critical juncture for the control of tumor growth and unregulated cell proliferation. ${ }^{5,21}$ Apoptotic cell death is considered to be a dynamic process that involves both early and late events. Membrane phosphatidylserine (PS) externalization is an early event during cell apoptosis that assists microglia to target cells for phagocytosis. ${ }^{22,23}$ This process occurs with the expression of the phosphatidylserine receptor (PSR) on microglia during oxidative stress, ${ }^{24-26}$ since blockade of PSR function in microglia prevents the activation of microglia. ${ }^{27,28}$ As an example, externalization of membrane PS residues occur in cells during periods of oxidative stress that involve anoxia, ${ }^{29}$ reactive oxygen species (ROS) exposure $^{30}$ and with agents that produce ROS, such as 6-hydroxydopamine. ${ }^{31}$ In contrast to cells with PS exposure, the cleavage of genomic DNA into fragments is considered to be a later event during apoptotic injury. ${ }^{20,32}$ Endonucleases responsible for DNA degradation have been identified and include the acidic, cation independent endonuclease (DNase II), cyclophilins, and the $97 \mathrm{kDa}$ magnesium-dependent endonuclease. In the nervous system, endonucleases include a constitutive acidic cation-independent endonuclease, a constitutive calcium/ magnesium-dependent endonuclease and an inducible magnesium dependent endonuclease. ${ }^{20,32}$

Interestingly, the induction of apoptosis in cells through FoxO proteins may require pathways aligned with oxidative stress. Oxidative stress is a result of the release of reactive oxygen species (ROS) that consist of oxygen free radicals and other chemical entities. Oxygen free radicals and mitochondrial DNA mutations have become associated with tissue injury, aging and accumulated toxicity for an organism. ${ }^{20}$ ROS include superoxide free radicals, hydrogen peroxide, singlet oxygen, nitric oxide and peroxynitrite. ${ }^{32}$
Most reactive species are produced at low levels during normal physiological conditions and are scavenged by endogenous antioxidant systems that include superoxide dismutase, glutathione peroxidase, catalase and small molecules, such as vitamins $\mathrm{C}, \mathrm{E}$, $\mathrm{D}_{3}$ and nicotinamide, the amide form of niacin or vitamin $\mathrm{B}_{3}{ }^{23,33,34}$ During periods of oxidative stress, FoxO transcription factors can lead to apoptosis, ${ }^{35}$ since forkhead transcription factors such as FoxO1 and FoxO3a must be present for oxidative stress to result in apoptotic cell injury. ${ }^{36}$ Under other conditions of oxidative stress, FoxO3a in conjunction with JNK have been shown to modulate an apoptotic ligand activating a Fas-mediated death pathway in cultured motoneurons, ${ }^{37}$ to lead to apoptosis through tumor-necrosis-factor-related apoptosis-inducing ligand (TRAIL) and BH3-only proteins Noxa and Bim in neuroblastoma cells, ${ }^{38}$ and to promote pro-apoptotic activity of $\mathrm{p} 53 .{ }^{39}$ Additional work shows that loss of FoxO expression during oxidative stress is protective to cells. For example, protein inhibition or gene knockdown of FoxO1 or FoxO3a can lead to reduction in ischemic infarct size in the brain, ${ }^{40}$ mediate protection of metabotropic glutamate receptors during vascular injury, ${ }^{41}$ enhance pancreatic $\beta$-cell or neuronal survival through $\mathrm{NAD}^{+}$precursors during oxidative stress ${ }^{42}$ and provide trophic factor protection with erythropoietin $(\mathrm{EPO})^{43}$ and neurotrophins. ${ }^{44}$ Yet, it should be noted that some studies suggest that the loss of FoxO1, FoxO3a and $\mathrm{FoxO} 4$ protein expression may actually lead to an increase in free radical release that can be responsible for oxidative stress. ${ }^{45}$ In addition, FoxO proteins may be protective during aging and exercise, since FoxO3a activity may enhance vascular smooth muscle antioxidant properties in aged animals and be beneficial to the cardiovascular system during physical exertion. ${ }^{46}$

\section{FoxO Proteins and Progenitor Cells}

The initial identification of FoxO proteins in soft-tissue tumors and leukemias, neoplasms now believed to harbor cancer stem cells for tumor self-renewal, ${ }^{47}$ suggests that FoxO proteins may be closely associated with the oversight of stem cell proliferation and differentiation. For example, either simultaneous deletion of Foxo1, Foxo3a and Foxo 4 or single deletion of Foxo3a in mice prevents the repopulation of hematopoietic stem cells and leads to apoptosis in these stem cell populations. ${ }^{45,48}$ Furthermore, vascular cytoprotective agents, such as the growth factor EPO, ${ }^{49-51}$ also may be required to modulate FoxO protein activity such as during erythroid progenitor cell development, ${ }^{52,53}$ suggesting that current clinical use of agents such as EPO during anemia or cancer may have less defined treatment implications for patients than originally anticipated. ${ }^{51,53}$ In cell culture and animal studies, EPO is cytoprotective in vascular cells and can stimulate postnatal neovascularization by increasing endothelial progenitor cell mobilization from the bone marrow. ${ }^{52-54}$ Interestingly, the ability of EPO to foster eythroid progenitor cell development is dependent upon the inhibition of FoxO3a activity, ${ }^{1,53}$ but also may require regulation of specific gene expression through an EPO-FoxO3a association to promote erythropoiesis in cultured cells..$^{55}$ In relation to the reproductive potential of an organism, deletion of the FoxO3a gene results in the depletion of oocytes and subsequent infertility. ${ }^{56}$ 
Other work using a mouse model of FoxO3a overexpression in oocytes further suggests that FoxO3a retards oocyte growth and follicular development and leads to anovulation and luteinization of unruptured follicles. ${ }^{57}$ These studies may suggest a role for FoxO proteins, and specifically FoxO3a, in relation to not only the development of cancer stem cell niches, but also in regards to oocyte and follicular cell maturation. For example, in a small percentage of women who suffer from premature ovarian failure mutations in FOXO3a and FOXO1a have been observed. ${ }^{58}$

\section{FoxO Proteins, Angiogenesis, Cardiovascular Function and Vascular Tone}

FoxO proteins also play a significant role to control new vessel growth that can impact upon cardiovascular development. New capillary formation from pre-existing vessels into an avascular area is a process known as angiogenesis that is present during embryogenesis, during menstruation and during pathological processes that involve wound healing, chronic inflammation and tumor growth. ${ }^{53,59}$ FoxO proteins are intimately involved in endothelial cell development and angiogenesis. For example, Foxo $3 a^{-1-}$ and Foxo $4^{-1-}$ mice develop without incidence and are indistinguishable from control littermates. However, mice that are singly deficient in Foxo1 die by embryonic day eleven and lack development of the vascular system. ${ }^{60}$ Additional studies illustrate that endothelial cell colonies in Foxo1-deficient mice fail to respond to vascular endothelial growth factor in a manner similar to wild-type endothelial cells, ${ }^{61}$ suggesting that FoxOs are necessary for the development of vascular cells as well as for the biological response to cellular mediators.

During cardiac development, FoxO proteins also appear to be necessary to modulate cardiomyocyte proliferation. Both FoxO1 and $\mathrm{FoxO} 3$ are expressed during embryonic through prenatal stages in the developing myocardium. The expression of these FoxO proteins is believed to negatively regulate cardiomyocyte growth, since overexpression of FoxO1 blocks cardiomyocyte proliferation but expression of dominant negative FoxO1 leads to enhanced cardiomyocyte growth. ${ }^{62}$ These observations may provide clues into the roles of FoxO proteins during cardiac hypertrophy. Atrogin-1, a protein that can block cardiac hypertrophy, may rely upon the upregulation of Foxo1 and Foxo3a to disrupt cardiac hypertrophy, since mice lacking atrogin-1 are susceptible to cardiac hypertrophy and do not yield increased expression of Foxo1 and Foxo3a. ${ }^{63}$

In regards to smooth muscle cell growth, Foxo3a has been demonstrated to block vascular smooth muscle proliferation and may lessen the effects from disorders such as atherosclerosis and hypertension. In a rat balloon carotid arterial injury model, gene transfer of FoxO3a can inhibit neointimal hyperplasia through the prevention of vascular smooth muscle growth. ${ }^{64}$ However, not all FoxO proteins may exert an inhibitory effect upon vascular smooth muscle cells. FoxO4 may inhibit smooth muscle cell differentiation through the repression of the transcriptional coactivator of smooth muscle genes myocardin, ${ }^{65}$ but other work suggests that FoxO4 also can increase matrix metalloproteinase 9 expression to promote vascular smooth muscle migration and foster neointimal hyperplasia. ${ }^{66}$
In light of the ability of FoxO proteins to regulate vascular smooth muscle cell proliferation, these transcription factors may have a significant clinical role in regards to disorders that involve hypertension and cardiac failure. Vascular smooth muscle cells are vital for the regulation of vascular tone and systemic arterial blood pressure. For example, high flow states in vessels can reduce FoxO1 activity, resulting in the potential proliferation of vascular smooth muscle cells, vascular neointimal hyperplasia and subsequent pathological states such as hypertension. ${ }^{67}$ In fact, $\alpha 1$-adrenergic agonists that increase systemic blood pressure can have the reverse effect and stimulate the expression of FoxO1 and its nuclear translocation that ultimately may lead to apoptotic endothelial cell injury. ${ }^{68}$ In addition, more than moderate levels of vessel cyclic stretch that can occur during hypertension may lead to the phosphorylation and inhibition of Foxo1 and Foxo3a in smooth muscle cells to further contribute to pathological smooth muscle cell proliferation. ${ }^{69}$ Furthermore, in human as well as murine models of cardiac failure, increased expression of Fox transcription factors, such as FoxO1a, have been observed to suggest a potential association of FoxO proteins with imminent cardiac failure. ${ }^{70}$

\section{FoxO Proteins and Regulation of Immunity}

Forkhead transcription factors have an important role in maintaining immune system function. For example, the forkhead family member FoxP3 can control the development and function of thymic-derived CD4(+)CD25(+) regulatory $\mathrm{T}$ cells (Treg) that impart autoimmunity. Loss of FoxP3 can result in autoimmune disorders. ${ }^{71}$ In addition, recent work identifies the expression of FoxP3 in tumor cells, such as melanoma, ${ }^{72}$ as well as in Tregs which may significantly affect patient mortality since the increased presence of Tregs in cancer patients combined with FoxP3 expression in tumors may impair antitumor autoimmune responses and lead to high mortality. ${ }^{73}$

In regards to FoxO proteins, these forkhead transcription factors also may influence early apoptotic membrane PS externalization. The ability to regulate early apoptotic membrane PS exposure ${ }^{27}$ and inflammatory cell activity 22 can ultimately affect cell survival since activated immune cells can lead to the phagocytic removal of tumor cells. ${ }^{24,32}$ Inflammatory cells, such as macrophages or microglia, require the activation of intracellular cytoprotective pathways to proliferate and remove injured cells. ${ }^{25,74}$ At times, this can be a beneficial process and form a barrier for the removal of foreign microorganisms and promote tissue repair during cell injury. 33,52 However, inflammatory cells also may lead to cellular damage through the generation of ROS and through the production of cytokines. ${ }^{52}$ Interestingly, in mice deficient for Foxo3a, lymphoproliferation, organ inflammation of the salivary glands, lung and kidney, and increased activity of helper $\mathrm{T}$ cells results, supporting an important role for FoxO3a in preventing $\mathrm{T}$ cell hyperactivity. ${ }^{75}$ FoxO3a also appears to be necessary for neutrophil activity, since Foxo3a null mice are resistant to models of neutrophilic inflammation that involve immune complex-mediated inflammatory arthritis. ${ }^{76}$

In clinical studies, patients with rheumatoid arthritis and osteoarthritis show phosphorylation of FOXO3a in T lymphocytes as well as FOXO1 and FOXO4 in synovial macrophages, 
suggesting that loss of functional FOXO family members may lead to inflammatory cell activation in these disorders. ${ }^{77}$ FOXO1 gene transcript levels also are downregulated in peripheral blood mononuclear cells of patients with systemic lupus erythematosus and rheumatoid arthritis, ${ }^{78}$ illustrating a potential etiology through the loss of functional FOXO proteins for these disorders and possibly providing a biomarker of disease activity. Other work has demonstrated that FOXO1 protein regulates L-selectin expression that can regulate human T lymphocyte trafficking. ${ }^{79}$ More importantly, studies suggest a relationship between the regulation of immune system activity and the induction of apoptotic pathways that are dependent upon FoxO proteins. Prevention of inflammatory activation and apoptosis in the nervous system such as in systemic lupus erythematosus in animal models may require the upregulation of different Fox proteins, such as FoxJ1 and FoxO3a, that can block NFKB activation and interferon-gamma secretion. ${ }^{80}$ FoxO proteins also may work in concert with Fas signaling to clear activated $\mathrm{T}$ cells following a decrease in cytokine stimulation in patients with autoimmune lymphoproliferative syndromes, ${ }^{81}$ suggesting that activation of specific FoxO proteins may be beneficial for autoimmune disorders but may impair treatments designed to target tumor cells through immune mediated pathways.

\section{FoxO Proteins, Diabetes and Modulation of Cellular Metabolism}

DM represents a significant health concern for both young and older populations. ${ }^{82,83}$ Approximately 16 million individuals in the US and more than 165 million individuals worldwide suffer from DM. By the year 2030, it is predicted that more than 360 million individuals will be afflicted with DM and its debilitating conditions. Type $2 \mathrm{DM}$ represents at least 80 percent of all diabetics and is dramatically increasing in incidence as a result of changes in human behavior and increased body mass index. ${ }^{33,82}$ Type 1 insulin-dependent DM is present in 5-10 percent of all diabetics, but is increasing in adolescent minority groups. ${ }^{33,82}$ Furthermore, the incidence of undiagnosed diabetes and impaired glucose tolerance in the population raises additional concerns.

Patients with DM can develop significant neurodegenerative $e^{33,84,85}$ and cardiovascular disease. ${ }^{33,86}$ Interestingly, the development of insulin resistance and the complications of DM can be the result of cellular oxidative stress. ${ }^{33,82}$ Hyperglycemia can lead to increased production of ROS in endothelial cells, liver cells and pancreatic $\beta$-cells. ${ }^{33,82,83}$ Recent clinical correlates support these experimental studies to show that elevated levels of ceruloplasmin are suggestive of increased ROS. ${ }^{33,82,83}$ Furthermore, acute glucose swings in addition to chronic hyperglycemia can trigger oxidative stress mechanisms, illustrating the importance for therapeutic interventions during acute and sustained hyperglycemic episodes. ${ }^{33,82}$

Early work with FoxO proteins has shown that metabolic signaling with these transcription factors is conserved among multiple species including Caenorhabditis elegans, Drosophila melanogaster and mammals. FoxO proteins are homologous to the transcription factor DAuer Formation-16 (DAF-16) in the worm Caenorhabditis elegans that can determine metabolic insulin signaling and lead to lifespan extension, ${ }^{87,88}$ suggesting a significant role for FoxO proteins in relation to mammalian cell function. ${ }^{5,11}$ In fact, FoxO proteins can stimulate the insulin-like growth factor binding protein-1 (IGFBP1) promoter by binding to the insulin-responsive sequence (IRS). ${ }^{89}$ Both insulin and insulinlike growth factor-1 (IGF-1) can suppress this activity through activation of Akt. ${ }^{89,90}$

In clinical studies, analysis of the genetic variance in FOXO1a and $\mathrm{FOXO} 3 \mathrm{a}$ on metabolic profiles, age-related diseases, fertility, fecundity and mortality have observed higher HbAlc levels and increased mortality risk associated with specific haplotypes of FOXO1a. ${ }^{91}$ These clinical observations may coincide with the demonstration in human endothelial progenitor cells that elevated glucose levels can reduce post-translational phosphorylation of FOXO1, FOXO3a and FOXO4 and allow for the nuclear translocation of these proteins to initiate an apoptotic program in endothelial progenitor cells. ${ }^{92}$ In experimental models, FoxO proteins may prevent the toxic effects of high serum glucose levels. Interferon-gamma driven expression of tryptophan catabolism by cytotoxic T lymphocyte antigen 4 may activate Foxo3a to protect dendritic cells from injury in nonobese diabetic mice. ${ }^{93}$ Additional studies have demonstrated that adipose tissue-specific expression of Foxol in mice improved glucose tolerance and sensitivity to insulin during an elevated fat diet. $^{94}$ FoxO proteins also may protect against diminished mitochondrial energy levels known to occur during insulin resistance such as in the elderly populations. ${ }^{33,82,83}$ In caloric restricted mice that have decreased energy reserves, Foxo1, Foxo3a and Foxo4 mRNA levels were noted to progressively increase over a two year course. ${ }^{3}$ These observations complement studies in Drosophila and mammalian cells that demonstrate an increase in insulin signaling to regulate cellular metabolism during the upregulation of FoxO1 expression. ${ }^{95}$

However, the ability for FoxO proteins to maintain proper physiologic controls over cellular metabolism may be limited and occur only during specific circumstances. For example, mice with a constitutively active Foxo 1 transgene have increased microsomal triglyceride transfer protein and elevated plasma triglyceride levels. ${ }^{96}$ Studies in cardiomyocytes also suggest detrimental results with enhanced FoxO activity. Increased transcriptional activity of FoxO1, such as by the Sirt1 activator resveratrol, can diminish insulin mediated glucose uptake and result in insulin resistance. ${ }^{97}$ In addition, overexpression of Foxo1 in skeletal muscles of mice can lead to reduced skeletal muscle mass and poor glycemic control, ${ }^{98}$ illustrating that activation of FoxO proteins also may impair cellular energy reserves. Additional investigations that block the expression of Foxol in normal and cachectic mice ${ }^{99}$ or reduce FoxO3 expression ${ }^{100}$ show the reverse with an increase in skeletal muscle mass or resistance to muscle atrophy. These results become especially relevant in patients with cancer and cachexia, since FoxO protein expression may further muscle wasting for these individuals. Given these concerns, one potential agent to consider for the maintenance of cellular metabolism in cancer patients is nicotinamide, ${ }^{23,101}$ an agent that also can inhibit FoxO protein activity. ${ }^{42}$ In patients with DM, oral nicotinamide protects $\beta$-cell function, prevents clinical disease in islet-cell antibody-positive first-degree relatives of type-1 $\mathrm{DM}$, and can reduce $\mathrm{HbA}_{1 \mathrm{c}}$ levels. ${ }^{23,82,101}$ 
Nicotinamide, which is closely linked to cell longevity pathways, ${ }^{102,103}$ may derive its protective capacity through two separate mechanisms of post-translational modification of FoxO3a. Nicotinamide not only can maintain phosphorylation of FoxO3a and inhibit its activity, but also can preserve the integrity of the FoxO3a protein to block FoxO3a proteolysis that can yield pro-apoptotic amino-terminal fragments. ${ }^{42}$

\section{Fox0 Proteins, Aging and Longevity}

FoxO proteins also have been associated with cell longevity and aging as shown by early studies linking DAF-16 in Caenorhabditis elegans to increased longevity. ${ }^{11,104-106}$ However, the relationship between FoxO transcription factors and proteins that increased cellular lifespan has been met with controversy. Sirt1 is a NAD+dependent deacetylase and the mammalian ortholog of the silent information regulator 2 (Sir2) protein associated with increased lifespan in yeast. Some studies suggest that stimulation of Sirt1 during starvation is dependent upon FoxO3a activity as well as p53. ${ }^{107}$ In contrast, other work has shown in cell culture that Sirt1 may repress the activity of FoxO1, FoxO3a and FoxO4, suggesting that cellular longevity may benefit from reduction in FoxO protein generated apoptosis. ${ }^{108}$ Additional studies offer alternative views to illustrate that Sirt1 binds to FoxO proteins, such as FoxO4, to catalyze its deacetylation and enhance FoxO4 activity while acetylation of FoxO4 by cyclic-AMP responsive element binding (CREB)-binding protein serves to inhibit FoxO4 transcriptional activity. ${ }^{11,104-106}$

FoxO proteins may be protective during aging, cell senescence and exercise. In cultured human dermal fibroblasts, gene silencing of FoxO3a protein results in cell morphology consistent with cell senescence, cell population doubling times, and the generation of ROS, suggesting that FoxO protein activity may be required to extend cell longevity and limit oxidative stress. ${ }^{109}$ Additional work in animal models of aging demonstrates a reduction in Sirt1 in the heart, but no significant change in FoxO3a expression with advanced age. However, during exercise training, an upregulation of FoxO3a and Sirt1 activity is observed in the heart, ${ }^{46}$ suggesting that the benefits of physical activity for the cardiovascular system may be associated with FoxO proteins. Interestingly, increased levels of Sirt1 less than 7.5-fold can be associated with expression of catalase, an anti-oxidant that is controlled by FoxOla to possibly reduce cell injury during oxidative stress. Yet, elevated levels of Sirt1 at 12.5-fold can result in cardiomyocyte apoptosis and decreased cardiac function. ${ }^{110}$ In addition, $\mathrm{FoxO}$ proteins may be protective during aging, since loss of FoxO3a activity in explanted vascular smooth muscle of aged animals may limit tissue antioxidant properties through decreased manganese superoxide dismutase and lead to enhanced cell injury with aging. ${ }^{111}$ Extension of cellular lifespan that depends upon the prevention of cell senescence at least in primary human cultured vascular cells also may require the negative regulation of Akt to allow for the activation of FoxO3a. ${ }^{112}$

\section{FoxO Proteins and Uncontrolled Cell Growth}

FoxO proteins represent important targets for several disorders. Yet, high on this list is the ability to modulate tumor cell growth in light of the ability of FoxO proteins to lead to apoptosis and block cell cycle progression. For example, FoxO3a and FoxO4 can promote cell cycle arrest in mouse myoblastic cell lines through modulation of growth-arrest and DNA-damage-response protein 45. 5,52 Treatment of chronic myelogenous leukemia cell lines with the Bcr-Abl tyrosine kinase inhibitor imatinib requires FoxO3a activation to antagonize cell proliferation and promote apoptotic cell death through increased TRAIL production. ${ }^{113}$ In addition, the transcription factor E2F-1 that controls the induction of the cell cycle has been reported in cell lines to increase the endogenous expression of FoxO1 and FoxO3a to lead to cell cycle arrest. ${ }^{114}$ In contrast, the loss of FoxO3a activity in association with c-myc, p27 and nuclear factor- $\mathrm{KB}(\mathrm{NF \kappa B})$ can result in cell cycle induction and malignant transformation of mouse cells in the presence of oncogene activation. ${ }^{5,11}$ Other work suggests that FoxO proteins utilize the p53 upstream regulator p19(Arf) through myc to block cell cycle induction and lymphoma progression. ${ }^{115}$

In regards to cancer cell progression, studies with prostate cancer have shown that the tumor suppressor phosphatase and tensin homolog deleted on chromosome ten (PTEN) is mutated in approximately eighty percent of tumors with the loss of FOXO1 and FOXO3a activity. In cell cultures, overexpression of FoxO1 and $\mathrm{FoxO} 3 \mathrm{a}$ in prostrate tumor cell lines also leads to apoptosis, suggesting that FoxO1 and FoxO3a are necessary for limiting prostate cell tumor growth. ${ }^{6}$ In addition, it has been shown that inhibition of FoxO3a activity can result in enhanced prostate tumor cell growth ${ }^{116}$ while agents that increase FoxO3a activity in both androgen sensitive and androgen insensitive prostate cell lines prevent prostate cancer cell progression. ${ }^{117}$ Furthermore, therapeutic strategies that rely upon the overexpression of a nonphosphorylatable form of FoxO3a that cannot be inactivated can sensitize prostate cancer cells to androgen-withdrawal-induced apoptosis. ${ }^{118}$ However, it should be noted that in prostate cell lines FoxO3a can be a positive regulator of androgen receptor expression and therefore may play a complex role in prostate cancer cell proliferation and growth inhibition. ${ }^{119}$ Other factors that control FoxO protein function also may play a role during prostate tumor progression. In prostate cancer cells, cyclin-dependent kinase 1 (CDK1) can become overexpressed and subsequently phosphorylate FOXO1 to block its transcriptional activity and contribute to prostate tumorigenesis. ${ }^{120}$ In a similar manner, it has been shown that astrocyte-elevated gene-1 (AEG-1) can be upregulated in clinical prostate cancer, ${ }^{121}$ possibly lead to activation of Akt that suppresses $\mathrm{FOXO} 3 \mathrm{a}^{122}$ and apoptosis in prostate tumor cells.

Initial investigations of $\mathrm{FOXO} 3 \mathrm{a}$ in clinical breast cancer suggested that activation of $\mathrm{FOXO} 3 \mathrm{a}$ was associated with lymph nodal metastasis and a poor prognosis. ${ }^{123}$ In contrast to these observations, other studies reported that $\mathrm{FOXO} 3$ a was inactivated by IKK and that inactivation of FOXO3a was associated with a poor prognosis in breast cancer, ${ }^{124}$ suggesting that $\mathrm{FOXO} 3 \mathrm{a}$ sub-cellular localization and pathways that enhance its activity could be used not only as prognostic assays but also as therapeutic targets. Other work in breast cancer cells demonstrate the tumor repressive ability of FoxOs by illustrating that increased activity of FoxO3a in association with JNK in breast cancer cell lines $^{125}$ or in association with cyclin-dependent kinase inhibitor 
p27 in isolated human breast cancer cells can prevent breast cancer growth. ${ }^{126}$ In addition, FoxO proteins may be able to modulate estrogen function and indirectly block breast cancer growth. Overexpression of FoxO3a in breast cancer cell lines can decrease the expression of estrogen receptor regulated genes and inhibits 17beta-estradiol (E2)-dependent breast cancer growth. ${ }^{127}$

In addition to the ability to inhibit prostate and breast tumor growth, FoxO proteins may represent a viable option to control tumor progression in other tissues. FoxO proteins can function as redundant repressors of tumor growth. For example, somatic deletion in mice of Foxo1, Foxo3a and Foxo 4 results in the growth of thymic lymphomas and hemangiomas. ${ }^{128}$ Other work illustrates that FoxO3a activation in colon carcinoma cell lines prevents tumor proliferation through Myc target genes that involve the $\mathrm{Mad} / \mathrm{Mxd}$ family of transcriptional repressors. ${ }^{129}$ In addition, the loss of FoxO3a activity may participate in oncogenic transformation in B-chronic lymphocytic leukemia ${ }^{130}$ and in the progression of chronic myelogenous leukemia cell lines. ${ }^{113}$ Furthermore, studies suggest that some proteins, such as the Kaposi's sarcomaassociated herpes virus latent protein LANA2, may specifically block the transcriptional activity of FoxO3a to lead to tumor growth. ${ }^{131}$ In cell models of endometrial cancer, pre-sensitization of cells to block Akt activation and foster transcription activity of FoxO1 enhances the effect of chemotherapy to limit tumor growth. ${ }^{132}$

\section{Fox0 Proteins and Post-Translational Pathways}

Post-translational modulation of FoxO proteins involves pathways associated with phosphorylation, acetylation and ubiquitylation. ${ }^{5,11,104,106,133}$ The serine-threonine kinase protein kinase $\mathrm{B}(\mathrm{Akt})$ is a primary mediator of phosphorylation of FoxO1, FoxO3a and FoxO4 that can block activity of these proteins. ${ }^{11,134}$ Activation of Akt is usually cytoprotective, such as during hyperglycemia, ${ }^{135}$ hypoxia, ${ }^{136} \beta$-amyloid $(A \beta)$ toxicity, ${ }^{137}$ cardiomyopathy, ${ }^{138}$ cellular aging ${ }^{139}$ and oxidative stress. ${ }^{22,28,140}$ Akt can prevent cellular apoptosis through the phosphorylation of FoxO proteins. ${ }^{35}$ Post-translational phosphorylation of FoxO proteins will maintain FoxO transcription factors in the cytoplasm by association with 14-3-3 proteins and prevent the transcription of pro-apoptotic target genes. ${ }^{43,51}$ An exception to these observations involving the subcellular trafficking of FoxO proteins involves FoxO6. This FoxO protein usually resides in the nucleus of cells and is phosphorylated by Akt in the nucleus. FoxO6 does not contain a conserved C-terminal Akt motif which limits nuclear shuttling of this protein, but FoxO6 transcriptional activity can be blocked by growth factors independent of shuttling to the cytosol through a FoxO6 N-terminal Akt site. ${ }^{141}$
Modulation of Akt activity also oversees apoptotic pathways of caspases that may offer an alternative mechanism to regulate FoxO proteins 142 (Fig. 1). Caspases are a family of cysteine proteases that are synthesized as inactive zymogens that are proteolytically cleaved into subunits at the onset of apoptosis. ${ }^{101,143,144}$ The caspases 1 and 3 have been linked to the apoptotic pathways of genomic DNA cleavage, cellular membrane PS exposure and activation of inflammatory cells. ${ }^{27,145,146}$ Caspase pathways may be tied to the forkhead transcription factor FoxO3a since increased activity of FoxO3a can result in cytochrome $c$ release and caspase-induced apoptotic death. ${ }^{38,41-43}$ Pathways that can inhibit caspase 3 activity appear to offer a unique regulatory mechanism (Fig. 1). For example, recent work suggests that cell death pathways that rely upon FoxO3a also appear to involve caspase 3 activation. ${ }^{147}$ Prior studies suggest that not only does FoxO3a activity promote caspase-induced apoptotic death, ${ }^{38,41-43}$ but also demonstrate that inhibition of caspase 3 has been shown to maintain the phosphorylated "inactive" state of FoxO3a to prevent cell injury. ${ }^{41-43}$ Other work has shown that caspase 3 activity and cleavage is promoted during transfection of a triple mutant FoxO3a expression in which three phosphorylation sites have been altered to prevent inactivation of FoxO3a. ${ }^{148}$ Recent work adds further insight to these studies by illustrating that FoxO3a may control early activation and subsequent apoptotic injury in microglia during amyloid $(A \beta)$ exposure through caspase 3. ${ }^{147}$ Since $A \beta$ exposure can facilitate the cellular trafficking of FoxO3a from the cytoplasm to the cell nucleus to potentially lead to "proapoptotic" programs by this transcription factor, ${ }^{147}$ one program 
in particular that may be vital for apoptotic injury appears to involve the activation of caspase $3 . \mathrm{A} \beta$ exposure leads to a rapid and significant increases in caspase 3 activity with six hours following $\mathrm{A} \beta$ administration, but that this induction of caspase 3 activity by $\mathrm{A} \beta$ requires FoxO3a, since loss of $\mathrm{FoxO} 3 \mathrm{a}$ through gene silencing prevents the induction of caspase 3 activity by $A \beta$.

Post-translational modulation of FoxO proteins also requires pathways associated with ubiquitylation and acetylation. ${ }^{149,150} \mathrm{Akt}$ phosphorylation of FoxO proteins not only retains these transcription factors in the cytoplasm, but also leads to ubiquitination and degradation through the $26 \mathrm{~S}$ proteasome. ${ }^{104,150}$ In the absence of Akt, IкB kinase (IKK) also can directly phosphorylate and block the activity of FoxO proteins, such as FoxO3a.,11 This leads to the proteolysis of FoxO3a via the Ub-dependent proteasome pathway. 5,11,104,106,133 The serum- and glucocorticoid-inducible protein kinase $(\mathrm{Sgk})$, a member of a family of kinases termed AGC (protein kinase A/protein kinase G/protein kinase C) kinases which includes Akt, also can phosphorylate and retain FoxO3a in the cytoplasm. ${ }^{151}$ Knowledge that Sgk and Akt can phosphorylate FoxO3a at different sites may offer new opportunities to more effectively prevent apoptotic cell injury that may be mediated by FoxO3a activity. Yet, phosphorylation of FoxO proteins does not always lead to negative regulation. The protein kinase mammalian sterile 20-like kinase-1 also can phosphorylate FoxO proteins directly and lead to their activation. ${ }^{152}$ The ability of sterile 20-like kinase-1 to activate FoxO proteins may be linked to c-Jun $\mathrm{N}$-terminal kinase (JNK), since sterile 20 -like kinase-1 can increase JNK activation. ${ }^{153}$ FoxO proteins also are acetylated by histone acetyltransferases that include p300, the CREB-binding protein (CBP), and the CBP-associated factor and are deacetylated by histone deacetylases, such as Sirt1, a NAD ${ }^{+}$-dependent deacetylase and the mammalian ortholog of the silent information regulator 2 (Sir2) protein. ${ }^{5}$ Acetylation of FoxO proteins provides another avenue for the control of these proteins. Once acetylated such as by $\mathrm{CBP}$, FoxO proteins may translocate to the cell nucleus but have diminished activity since acetylation of lysine residues on FoxO proteins has been shown to limit the ability of FoxO proteins to bind to DNA. ${ }^{154}$ In addition, acetylation can increase phosphorylation of FoxO proteins by Akt. ${ }^{154}$

\section{FoxO Proteins and Unique Signaling Pathways}

FoxO proteins have recently been associated with other unique signal transduction pathways that involve proteins derived from the Drosophila Wingless (Wg) and the mouse Int-1 genes. ${ }^{133}$ The Wnt proteins are secreted cysteine-rich glycosylated proteins that can control cell proliferation, differentiation, survival and tumorigenesis. ${ }^{59,155}$ More than eighty target genes of Wnt signaling pathways have been demonstrated in human, mouse, Drosophila, Xenopus and zebrafish. These genes are present in several cellular populations, such as neurons, cardiomyocytes, endothelial cells, cancer cells and pre-adipocytes. ${ }^{84}$ At least 19 of $24 \mathrm{Wnt}$ genes that express Wnt proteins have been identified in the human. ${ }^{59,155,156}$

The canonical Wnt pathway controls target gene transcription through $\beta$-catenin. ${ }^{59,155}$ It is the $\beta$-catenin pathway that appears to tie FoxO proteins and Wnt signaling together. ${ }^{21}$ For example, in relation to Alzheimer disease, $\mathrm{A} \beta$ is toxic to cells ${ }^{29,137}$ and is associated with the phosphorylation of FoxO1 and FoxO3a that can be blocked with ROS scavengers. ${ }^{157}$ A common denominator in the pathways linked to $\mathrm{A} \beta$ toxicity involves Wnt signaling through $\beta$-catenin. $\beta$-catenin may increase FoxO transcriptional activity and competitively limit $\beta$-catenin interactionwith members of the lymphoid enhancer factor/T cell factor family ${ }^{158}$ and $\beta$-catenin also has been demonstrated to be necessary for protection against $\mathrm{A} \beta$ toxicity in neuronal cells. ${ }^{29}$

Additional shared signal transduction pathways between Wnt and FoxO proteins involve Akt. Processes that involve cellular proliferation, injury and immune system modulation with FoxO proteins ${ }^{159}$ also have parallel cellular pathways with Wnt and Akt. For example, Wnt relies upon Akt for the proliferation and differentiation of cardiomyocytes. ${ }^{160}$ In addition, reduction in tissue injury during pressure overload cardiac hypertrophy and the cytoprotective benefits of cardiac ischemic preconditioning also appear to depend upon Akt. ${ }^{59,155}$ Furthermore, Wnt overexpression can independently increase the phosphorylation and the activation of Akt to promote cellular protection and control microglial activation. ${ }^{29}$

Yet, other members of the forkhead family in addition to FoxOs also rely upon Wnt signaling in several scenarios that involve regulated as well as unchecked cell proliferation. ${ }^{59,155,161}$ For example, FoxD3 is activated by the Wnt pathway to control neural plate development ${ }^{162}$ and Foxl1 activates the Wnt/ $\beta$-catenin pathway to increase extracellular proteoglycans, promote gastrointestinal cell proliferation, and possibly foster carcinogenesis. ${ }^{163}$ The Wnt pathway also utilizes forkhead members to modulate endocrine activity and can activate Foxn 1 for regulatory control of thymic function. ${ }^{164}$ In other examples of cell development, Wnt signaling has been shown to rely upon Foxf1 and Foxf2 during intestinal maturation in murine models. ${ }^{165}$ In addition, Foxa 2 in mice may be a significant component in early anterior-posterior axis polarization. ${ }^{166}$ Deregulation of Wnt alone also promotes activation of $\beta$-catenin that has been associated with the proliferation of medulloblastoma tumors. ${ }^{47}$ In addition, reduced expression of inhibitors of the Wnt pathway, such as axin, may foster lung cancer cell invasion. ${ }^{167}$ Multiple other studies also point to the activation of the Wnt pathway during gastric cancer. For example, Wnt5a expression has been correlated with advanced gastric cancer stages and a poor prognosis ${ }^{168}$ while experimental activation of the $\beta$-catenin pathway leads to the development of gastric tumors. ${ }^{169}$ In conjunction with forkhead proteins, loss of Foxl1 that can regulate the Wnt pathway and prevent $\beta$-catenin nuclear accumulation is believed to be a significant etiology for gastrointestinal tumorigenesis. ${ }^{163}$

\section{Future Perspectives}

FoxO proteins represent unique and exciting cellular targets that can control numerous processes such as angiogenesis, cardiovascular development, vascular tone, oxidative stress, stem cell proliferation, fertility, immunity and cancer. In relation to the treatment of cancer, the ability of FoxO proteins to control cell cycle progression and promote apoptosis illustrates the potential of FoxOs to become an important component for new strategies 
directed against tumorigenesis. For example, use of triple mutant FoxO1 or FoxO3a expression in which three phosphorylation sites have been altered to prevent inactivation of this protein has been proposed as a potential therapeutic agent against melanoma tumors ${ }^{148}$ and endometrial cancer. ${ }^{170}$ Other work also offers additional support for the use of $\mathrm{FoxO}$ proteins as biomarkers of cancer progression. As an example, downregulation of the phosphatidylinositol 3 kinase and Akt pathways have been associated with increased transcript levels for FOXO1a and FOXO3a in clinical prostate cancer samples and may indicate the onset of pre-cancerous changes or the progression of on-going tumor growth. ${ }^{171}$ Although loss of Akt activity in prostate cancer cells can result in enhanced FoxO3a activity and subsequent apoptosis of tumor cells, ${ }^{121}$ it is conceivable that early stages of cancer may lead to reduced Akt activity with insufficient levels of active forkhead transcription factors to limit tumor progression. In addition, the early and persistent expression of phosphorylated FOXO1a in gastric tumors may not only indicate the onset of cancer, but also suggest an improved prognosis for patients. ${ }^{172}$

In addition, the known mutations in FoxO proteins that exist in several disease entities may provide novel insights for therapeutic strategies that can address other disorders. Further analysis in larger populations of patients with premature ovarian failure, diabetes, or stroke could enhance our understanding of the role of FoxO proteins in these disorders. When one considers the role of FoxO proteins at the cellular level such as in cardiac and endothelial cells, targeting the activity of FoxO1, FoxO3a or FoxO4 may prevent the onset of pathological cardiac hypertrophy and neointimal hyperplasia that may result in atherosclerosis. Interestingly, new work suggests that the utilization and combination of multiple biomarkers may improve risk assessment for patients suffering from cardiovascular disorders. ${ }^{173}$ These studies illustrate that FoxO proteins may serve as biomarkers of disease activity such as in individuals with imminent cardiac failure. ${ }^{70}$

Yet, FoxO proteins have divers roles and at times may be detrimental to clinical outcome. For example, FoxO protein inhibition of cell cycle progression may not consistently lead to apoptotic cell death. Some investigations suggest that during oxidative stress, FoxO3a activation in association with Sirt1 can lead to cell cycle arrest, but not result in apoptotic cell injury. ${ }^{174}$ Furthermore, during hypoxic stress, forkhead transcription factors, such as FOXO3a, may potentiate anti-apoptotic pathways in breast cancer cells to further tumor growth. ${ }^{175}$ FoxO proteins also have been linked to potential chemotherapy drug resistance. Increased expression of MDR1 (P-glycoprotein) has been associated with chemotherapy drug resistance in breast cancer cells and recent work shows that FoxO1 can stimulate the transcriptional activity of MDR1 that may promote increased tolerance of tumor cells. ${ }^{176}$ In addition, the common pathways shared between Wnt and forkhead proteins may have another side that impacts upon the ability to control tumor growth. ${ }^{155,161}$ FoxO proteins may assist with $\beta$-catenin activation in the Wnt pathway and lead to tumor cell proliferation. ${ }^{59}$ In the presence of Wnt deregulation and increased $\beta$-catenin activity, tumorigenesis may ensue, such as with the proliferation of medulloblastoma tumors. ${ }^{47}$ As a result, prediction of biological outcomes during FoxO protein involvement may not be consistently known and may be influenced by multiple parameters such as tissue characteristics, cellular metabolic state and the age of an individual. These observations argue for further robust basic and clinical studies to further comprehend the potential fruits and failures for FoxO proteins as novel therapeutic strategies.

\section{Acknowledgements}

This research was supported by the following grants (K.M.): American Diabetes Association, American Heart Association (National), Bugher Foundation Award, Janssen Neuroscience Award, LEARN Foundation Award, MI Life Sciences Challenge Award, Nelson Foundation Award, NIH NIEHS (P30 ES06639), and NIH NINDS/NIA.

\section{References}

1. Castrillon DH, Miao L, Kollipara R, Horner JW, DePinho RA. Suppression of ovarian follicle activation in mice by the transcription factor Foxo3a. Science 2003; 301:215-8.

2. Furuyama T, Nakazawa T, Nakano I, Mori N. Identification of the differential distribution patterns of mRNAs and consensus binding sequences for mouse DAF-16 homologues. Biochem J 2000; 349:629-34.

3. Furuyama T, Yamashita H, Kitayama K, Higami Y, Shimokawa I, Mori N. Effects of aging and caloric restriction on the gene expression of Foxo1, 3 and 4 (FKHR, FKHRL1 and AFX) in the rat skeletal muscles. Microscopy research and technique 2002; 59:331-4.

4. Hoekman MF, Jacobs FM, Smidt MP, Burbach JP. Spatial and temporal expression of FoxO transcription factors in the developing and adult murine brain. Gene Expr Patterns 2006; 6:134-40.

5. Maiese K, Chong ZZ, Shang YC. OutFOXOing disease and disability: the therapeutic potential of targeting FoxO proteins. Trends Mol Med 2008; 14:219-27.

6. Modur V, Nagarajan R, Evers BM, Milbrandt J. FOXO proteins regulate tumor necrosis factor-related apoptosis inducing ligand expression. Implications for PTEN mutation in prostate cancer. J Biol Chem 2002; 277:47928-37.

7. Maiese K, Chong Z, Hou J, Shang Y. The "O" Class: Crafting clinical care with FoxO transcription factors. In: Forkhead Transcription Factors: Vital Elements in Biology and Medicine Maiese K, Ed., Landes Bioscience, Austin, TX 2009; (in press).

8. Biggs WH, 3rd, Cavenee WK, Arden KC. Identification and characterization of members of the FKHR (FOX O) subclass of winged-helix transcription factors in the mouse. Mamm Genome 2001; 12:416-25.

9. Weigel D, Jurgens G, Kuttner F, Seifert E, Jackle H. The homeotic gene fork head encodes a nuclear protein and is expressed in the terminal regions of the Drosophila embryo. Cell 1989; 57:645-58.

10. Kaestner KH, Knochel W, Martinez DE. Unified nomenclature for the winged helix/ forkhead transcription factors. Genes Dev 2000; 14:142-6.

11. Maiese K, Chong ZZ, Shang YC. "Sly as a FOXO": New paths with Forkhead signaling in the brain. Curr Neurovasc Res 2007; 4:295-302.

12. Parry P, Wei Y, Evans G. Cloning and characterization of the $t(X ; 11)$ breakpoint from a leukemic cell line identify a new member of the forkhead gene family. Genes Chromosomes Cancer 1994; 11:79-84.

13. Hillion J, Le Coniat M, Jonveaux P, Berger R, Bernard OA. AF6q21, a novel partner of the MLL gene in $\mathrm{t}(6 ; 11)(\mathrm{q} 21 ; \mathrm{q} 23)$, defines a forkhead transcriptional factor subfamily. Blood 1997; 90:3714-9.

14. Maiese K, Chong ZZ, Shang YC, Hou J. A "FOXO" in sight: Targeting Foxo proteins from conception to cancer. Med Res Rev 2009; 29:395-418.

15. Clark KL, Halay ED, Lai E, Burley SK. Co-crystal structure of the HNF-3/fork head DNA-recognition motif resembles histone H5. Nature 1993; 364:412-20.

16. Larson ET, Eilers B, Menon S, Reiter D, Ortmann A, Young MJ, et al. A winged-helix protein from Sulfolobus turreted icosahedral virus points toward stabilizing disulfide bonds in the intracellular proteins of a hyperthermophilic virus. Virology 2007; 368:249-61.

17. Jin C, Marsden I, Chen X, Liao X. Sequence specific collective motions in a winged helix DNA binding domain detected by $15 \mathrm{~N}$ relaxation NMR. Biochemistry 1998; 37:6179-87.

18. Tsai KL, Sun YJ, Huang CY, Yang JY, Hung MC, Hsiao CD. Crystal structure of the human FOXO3a-DBD/DNA complex suggests the effects of post-translational modification. Nucleic Acids Res 2007; 35:6984-94.

19. Wijchers PJ, Burbach JP, Smidt MP. In control of biology: Of mice, men and Foxes. Biochem J 2006; 397:233-46.

20. Chong ZZ, Li F, Maiese K. Oxidative stress in the brain: Novel cellular targets that govern survival during neurodegenerative disease. Prog Neurobiol 2005; 75:207-46. 
21. Maiese K, Chong ZZ, Shang YC, Hou J. Rogue proliferation versus restorative protection: Where do we draw the line for Wnt and forkhead signaling? Expert opinion on therapeutic targets 2008; 12:905-16.

22. Kang JQ, Chong ZZ, Maiese K. Critical role for Akt1 in the modulation of apoptotic phosphatidylserine exposure and microglial activation. Mol Pharmacol 2003; 64:557-69.

23. Maiese K, Chong ZZ. Nicotinamide: Necessary nutrient emerges as a novel cytoprotectant for the brain. Trends Pharmacol Sci 2003; 24:228-32.

24. Chong ZZ, Kang J, Li F, Maiese K. mGluRI targets microglial activation and selectively prevents neuronal cell engulfment through Akt and caspase dependent pathways. Curr Neurovasc Res 2005; 2:197-211.

25. Li F, Chong ZZ, Maiese K. Microglial integrity is maintained by erythropoietin through integration of Akt and its substrates of glycogen synthase kinase-3beta, beta-catenin and nuclear factor-kappaB. Curr Neurovasc Res 2006; 3:187-201.

26. Lin SH, Maiese K. The metabotropic glutamate receptor system protects against ischemic free radical programmed cell death in rat brain endothelial cells. J Cereb Blood Flow Metab 2001; 21:262-75.

27. Chong ZZ, Kang JQ, Maiese K. Erythropoietin fosters both intrinsic and extrinsic neuronal protection through modulation of microglia, Akt1, Bad and caspase-mediated pathways. Br J Pharmacol 2003; 138:1107-18

28. Kang JQ, Chong ZZ, Maiese K. Akt1 protects against inflammatory microglial activation through maintenance of membrane asymmetry and modulation of cysteine protease activity. J Neurosci Res 2003; 74:37-51.

29. Chong ZZ, Li F, Maiese K. Cellular demise and inflammatory microglial activation during beta-amyloid toxicity are governed by Wnt 1 and canonical signaling pathways. Cell Signal 2007; 19:1150-62.

30. Chong ZZ, Lin SH, Kang JQ, Maiese K. The tyrosine phosphatase SHP2 modulates MAP kinase p38 and caspase 1 and 3 to foster neuronal survival. Cell Mol Neurobiol 2003; 23:561-78.

31. Salinas M, Diaz R, Abraham NG, Ruiz de Galarreta CM, Cuadrado A. Nerve growth factor protects against 6-hydroxydopamine-induced oxidative stress by increasing expression of heme oxygenase-1 in a phosphatidylinositol 3-kinase-dependent manner. J Biol Chem 2003; 278:13898-904.

32. Chong ZZ, Maiese K. The Src homology 2 domain tyrosine phosphatases SHP-1 and SHP-2: diversified control of cell growth, inflammation and injury. Histol Histopathol 2007; 22:1251-67.

33. Maiese K. Diabetic stress: new triumphs and challenges to maintain vascular longevity. Expert Rev Cardiovasc Ther 2008; 6:281-4.

34. Slomka M, Zieminska E, Lazarewicz J. Nicotinamide and 1-methylnicotinamide reduce homocysteine neurotoxicity in primary cultures of rat cerebellar granule cells. Acta Neurobiol Exp (Wars) 2008; 68:1-9.

35. Maiese K, Chong ZZ, Hou J, Shang YC. Erythropoietin and oxidative stress. Curr Neurovasc Res 2008; 5:125-42.

36. Nakamura T, Sakamoto K. Forkhead transcription factor FOXO subfamily is essential for reactive oxygen species-induced apoptosis. Mol Cell Endocrinol 2007; 281:47-55.

37. Barthelemy C, Henderson CE, Pettmann B. Foxo3a induces motoneuron death through the Fas pathway in cooperation with JNK. BMC Neurosci 2004; 5:48.

38. Obexer P, Geiger K, Ambros PF, Meister B, Ausserlechner MJ. FKHRL1-mediated expression of Noxa and Bim induces apoptosis via the mitochondria in neuroblastoma cells. Cell Death Differ 2007; 14:534-47.

39. You H, Yamamoto K, Mak TW. Regulation of transactivation-independent proapoptotic activity of p53 by FOXO3a. Proc Natl Acad Sci USA 2006; 103:9051-6.

40. Won CK, Ji HH, Koh PO. Estradiol prevents the focal cerebral ischemic injury-induced decrease of forkhead transcription factors phosphorylation. Neurosci Lett 2006; 398:39-43.

41. Chong ZZ, Li F, Maiese K. Group I Metabotropic Receptor Neuroprotection Requires Akt and Its Substrates that Govern FOXO3a, Bim and beta-Catenin During Oxidative Stress. Curr Neurovasc Res 2006; 3:107-17.

42. Chong $\mathrm{ZZ}$, Lin $\mathrm{SH}$, Maiese $\mathrm{K}$. The $\mathrm{NAD}^{+}$precursor nicotinamide governs neuronal survival during oxidative stress through protein kinase $\mathrm{B}$ coupled to FOXO3a and mitochondrial membrane potential. J Cereb Blood Flow Metab 2004; 24:728-43.

43. Chong ZZ, Maiese K. Erythropoietin involves the phosphatidylinositol 3-kinase pathway, 14-3-3 protein and FOXO3a nuclear trafficking to preserve endothelial cell integrity. Br J Pharmacol 2007; 150:839-50.

44. Caporali A, Sala-Newby GB, Meloni M, Graiani G, Pani E, Cristofaro B, et al. Identification of the prosurvival activity of nerve growth factor on cardiac myocytes. Cell Death Differ 2008; 15:299-311.

45. Tothova Z, Kollipara R, Huntly BJ, Lee BH, Castrillon DH, Cullen DE, et al. FoxOs are critical mediators of hematopoietic stem cell resistance to physiologic oxidative stress. Cell 2007; 128:325-39.

46. Ferrara N, Rinaldi B, Corbi G, Conti V, Stiuso P, Boccuti S, et al. Exercise Training Promotes SIRT1 Activity in Aged Rats. Rejuvenation Res 2008; 11:139-50.

47. Sauvageot CM, Kesari S, Stiles CD. Molecular pathogenesis of adult brain tumors and the role of stem cells. Neurol Clin 2007; 25:891-924.

48. Miyamoto K, Araki KY, Naka K, Arai F, Takubo K, Yamazaki S, et al. Foxo3a Is Essential for Maintenance of the Hematopoietic Stem Cell Pool. Cell Stem Cell 2007; 1:101-12.
49. Arcasoy MO. The non-haematopoietic biological effects of erythropoietin. $\mathrm{Br}$ Haematol 2008; 141:14-31.

50. Cariou A, Claessens YE, Pene F, Marx JS, Spaulding C, Hababou C, et al. Early highdose erythropoietin therapy and hypothermia after out-of-hospital cardiac arrest: a matched control study. Resuscitation 2008; 76:397-404.

51. Maiese K, Li F, Chong ZZ. New avenues of exploration for erythropoietin. JAMA 2005; 293:90-5.

52. Maiese K, Chong ZZ, Li F, Shang YC. Erythropoietin: Elucidating new cellular targets that broaden therapeutic strategies. Prog Neurobiol 2008; 85:194-213.

53. Maiese K, Chong ZZ, Shang YC. Raves and risks for erythropoietin. Cytokine Growth Factor Rev 2008; 19:145-55.

54. Chong ZZ, Shang YC, Maiese K. Vascular injury during elevated glucose can be mitigated by erythropoietin and Wnt signaling. Curr Neurovasc Res 2007; 4:194-204.

55. Bakker WJ, van Dijk TB, Parren-van Amelsvoort M, Kolbus A, Yamamoto K, Steinlein P, et al. Differential regulation of Foxo3a target genes in erythropoiesis. Mol Cell Biol 2007; 27:3839-54.

56. Furukawa-Hibi Y, Yoshida-Araki K, Ohta T, Ikeda K, Motoyama N. FOXO forkhead transcription factors induce $\mathrm{G}(2)-\mathrm{M}$ checkpoint in response to oxidative stress. J Biol Chem 2002; 277:26729-32.

57. Liu L, Rajareddy S, Reddy P, Du C, Jagarlamudi K, Shen Y, et al. Infertility caused by retardation of follicular development in mice with oocyte-specific expression of Foxo3a. Development 2007; 134:199-209.

58. Watkins WJ, Umbers AJ, Woad KJ, Harris SE, Winship IM, Gersak K, et al. Mutational screening of FOXO3A and FOXO1A in women with premature ovarian failure. Fertility and sterility 2006; 86:1518-21.

59. Maiese K, Li F, Chong ZZ, Shang YC. The Wnt signaling pathway: Aging gracefully as a protectionist? Pharmacol Ther 2008; 118:58-81.

60. Hosaka T, Biggs WH, 3rd, Tieu D, Boyer AD, Varki NM, Cavenee WK, et al. Disruption of forkhead transcription factor (FOXO) family members in mice reveals their functional diversification. Proc Natl Acad Sci USA 2004; 101:2975-80.

61. Furuyama T, Kitayama K, Shimoda Y, Ogawa M, Sone K, Yoshida-Araki K, et al. Abnormal angiogenesis in Foxo1 (Fkhr)-deficient mice. J Biol Chem 2004; 279:34741-9.

62. Evans-Anderson HJ, Alfieri CM, Yutzey KE. Regulation of cardiomyocyte proliferation and myocardial growth during development by FOXO transcription factors. Circ Res 2008; 102:686-94

63. Li HH, Willis MS, Lockyer P, Miller N, McDonough H, Glass DJ, et al. Atrogin-1 inhibits Akt-dependent cardiac hypertrophy in mice via ubiquitin-dependent coactivation of Forkhead proteins. J Clin Invest 2007; 117:3211-23.

64. Abid MR, Yano K, Guo S, Patel VI, Shrikhande G, Spokes KC, et al. Forkhead transcription factors inhibit vascular smooth muscle cell proliferation and neointimal hyperplasia. J Biol Chem 2005; 280:29864-73.

65. Liu ZP, Wang Z, Yanagisawa H, Olson EN. Phenotypic modulation of smooth muscle cells through interaction of Foxo4 and myocardin. Dev Cell 2005; 9:261-70.

66. Li H, Liang J, Castrillon DH, DePinho RA, Olson EN, Liu ZP. FoxO4 regulates tumor necrosis factor alpha-directed smooth muscle cell migration by activating matrix metalloproteinase 9 gene transcription. Mol Cell Biol 2007; 27:2676-86.

67. Goettsch W, Gryczka C, Korff T, Ernst E, Goettsch C, Seebach J, et al. Flow-dependent regulation of angiopoietin-2. J Cell Physiol 2008; 214:491-503.

68. Morris JB, Kenney B, Huynh H, Woodcock EA. Regulation of the proapoptotic factor FOXO1 (FKHR) in cardiomyocytes by growth factors and $\alpha 1$-adrenergic agonists. Endocrinology 2005; 146:4370-6.

69. Sedding DG, Seay U, Fink L, Heil M, Kummer W, Tillmanns H, et al. Mechanosensitive p $27^{\text {Kip } 1}$ regulation and cell cycle entry in vascular smooth muscle cells. Circulation 2003; 108:616-22.

70. Hannenhalli S, Putt ME, Gilmore JM, Wang J, Parmacek MS, Epstein JA, et al. Transcriptional genomics associates FOX transcription factors with human heart failure. Circulation 2006; 114:1269-76.

71. Cools N, Ponsaerts P, Van Tendeloo VF, Berneman ZN. Regulatory T cells and human disease. Clin Dev Immunol 2007; 2007:89195.

72. Ebert LM, Tan BS, Browning J, Svobodova S, Russell SE, Kirkpatrick N, et al. The regulatory $\mathrm{T}$ cell-associated transcription factor FoxP3 is expressed by tumor cells. Cancer Res 2008; 68:3001-9.

73. Kono K, Kawaida H, Takahashi A, Sugai H, Mimura K, Miyagawa N, et al. CD4(+) $\mathrm{CD} 25$ high regulatory $\mathrm{T}$ cells increase with tumor stage in patients with gastric and esophageal cancers. Cancer Immunol Immunother 2006; 55:1064-71.

74. Chong ZZ, Li F, Maiese K. The pro-survival pathways of mTOR and protein kinase B target glycogen synthase kinase- $3 \beta$ and nuclear factor- $\kappa \mathrm{B}$ to foster endogenous microglial cell protection. Int J Mol Med 2007; 19:263-72.

75. Lin L, Hron JD, Peng SL. Regulation of NFkappaB, Th activation and autoinflammation by the forkhead transcription factor Foxo3a. Immunity 2004; 21:203-13.

76. Jonsson H, Allen P, Peng SL. Inflammatory arthritis requires Foxo3a to prevent Fas ligand-induced neutrophil apoptosis. Nat Med 2005; 11:666-71.

77. Ludikhuize J, de Launay D, Groot D, Smeets TJ, Vinkenoog M, Sanders ME, et al. Inhibition of forkhead box class $\mathrm{O}$ family member transcription factors in rheumatoid synovial tissue. Arthritis Rheum 2007; 56:2180-91. 


\section{A fork in the path: Developing therapeutic inroads with Fox0 proteins}

78. Kuo CC, Lin SC. Altered FOXO1 transcript levels in peripheral blood mononuclear cells of systemic lupus erythematosus and rheumatoid arthritis patients. Mol Med 2007; 13:561-6.

79. Fabre S, Carrette F, Chen J, Lang V, Semichon M, Denoyelle C, et al. FOXO1 regulates L-Selectin and a network of human $\mathrm{T}$ cell homing molecules downstream of phosphatidylinositol 3-kinase. J Immunol 2008; 181:2980-9.

80. Sela U, Dayan M, Hershkoviz R, Cahalon L, Lider O, Mozes E. The negative regulators Foxj1 and Foxo3a are upregulated by a peptide that inhibits systemic lupus erythematosus-associated T cell responses. Eur J Immunol 2006; 36:2971-80.

81. Bosque A, Aguilo JI, Alava MA, Paz-Artal E, Naval J, Allende LM, et al. The induction of Bim expression in human T-cell blasts is dependent on nonapoptotic Fas/CD95 signaling. Blood 2007; 109:1627-35.

82. Maiese K, Chong ZZ, Shang YC. Mechanistic insights into diabetes mellitus and oxidative stress. Curr Med Chem 2007; 14:1729-38.

83. Maiese K, Morhan SD, Chong ZZ. Oxidative stress biology and cell injury during type 1 and type 2 diabetes mellitus. Curr Neurovasc Res 2007; 4:63-71.

84. Maiese K. Triple play: Promoting neurovascular longevity with nicotinamide, WNT and erythropoietin in diabetes mellitus. Biomed Pharmacother 2008; 62:218-32.

85. Maiese K, Chong Z, Li F. Reducing oxidative stress and enhancing neurovascular longevity during diabetes mellitus. In: Neurovascular Medicine: Pursuing Cellular Longevity for Healthy Aging, Maiese K, Ed., Oxford University Press: New York, NY 2009; ISBN13: 978-0-19-532669-7, ISBN10: 0-19-532669-5.

86. Donahoe SM, Stewart GC, McCabe CH, Mohanavelu S, Murphy SA, Cannon CP, et al. Diabetes and mortality following acute coronary syndromes. JAMA 2007; 298:765-75.

87. Lin K, Dorman JB, Rodan A, Kenyon C. daf-16: An HNF-3/forkhead family member that can function to double the life-span of Caenorhabditis elegans. Science 1997; 278:1319-22.

88. Ogg S, Paradis S, Gottlieb S, Patterson GI, Lee L, Tissenbaum HA, et al. The Fork head transcription factor DAF-16 transduces insulin-like metabolic and longevity signals in C. elegans. Nature 1997; 389:994-9.

89. Guo S, Rena G, Cichy S, He X, Cohen P, Unterman T. Phosphorylation of serine 256 by protein kinase B disrupts transactivation by FKHR and mediates effects of insulin on insulin-like growth factor-binding protein-1 promoter activity through a conserved insulin response sequence. J Biol Chem 1999; 274:17184-92.

90. Nakae J, Park BC, Accili D. Insulin stimulates phosphorylation of the forkhead transcription factor FKHR on serine 253 through a Wortmannin-sensitive pathway. J Biol Chem 1999; 274:15982-5.

91. Kim JR, Jung HS, Bae SW, Kim JH, Park BL, Choi YH, et al. Polymorphisms in FOXO gene family and association analysis with BMI. Obesity (Silver Spring, Md) 2006; 14:188-93.

92. Marchetti V, Menghini R, Rizza S, Vivanti A, Feccia T, Lauro D, et al. Benfotiamine counteracts glucose toxicity effects on endothelial progenitor cell differentiation via Akt/ FoxO signaling. Diabetes 2006; 55:2231-7.

93. Fallarino F, Bianchi R, Orabona C, Vacca C, Belladonna ML, Fioretti MC, et al. CTLA4-Ig activates forkhead transcription factors and protects dendritic cells from oxidative stress in nonobese diabetic mice. J Exp Med 2004; 200:1051-62.

94. Nakae J, Cao Y, Oki M, Orba Y, Sawa H, Kiyonari H, et al. Forkhead transcription factor FoxO1 in adipose tissue regulates energy storage and expenditure. Diabetes 2008; 57:563-76.

95. Puig O, Tjian R. Transcriptional feedback control of insulin receptor by dFOXO/ FOXO1. Genes Dev 2005; 19:2435-46.

96. Kamagate A, Dong HH. Foxo1 integrates insulin signaling to VLDL production. Cell Cycle 2008; 7:3162-70.

97. Ni YG, Wang N, Cao DJ, Sachan N, Morris DJ, Gerard RD, et al. FoxO transcription factors activate Akt and attenuate insulin signaling in heart by inhibiting protein phosphatases. Proc Natl Acad Sci USA 2007; 104:20517-22.

98. Kamei Y, Miura S, Suzuki M, Kai Y, Mizukami J, Taniguchi T, et al. Skeletal muscle FOXO1 (FKHR) transgenic mice have less skeletal muscle mass, downregulated Type I (slow twitch/red muscle) fiber genes and impaired glycemic control. J Biol Chem 2004; 279:41114-23.

99. Liu CM, Yang Z, Liu CW, Wang R, Tien P, Dale R, et al. Effect of RNA oligonucleotide targeting Foxo-1 on muscle growth in normal and cancer cachexia mice. Cancer Gene Ther 2007; 14:945-52.

100. Sandri M, Lin J, Handschin C, Yang W, Arany ZP, Lecker SH, et al. PGC-1alpha protects skeletal muscle from atrophy by suppressing FoxO3 action and atrophy-specific gene transcription. Proc Natl Acad Sci USA 2006; 103:16260-5.

101. Li F, Chong ZZ, Maiese K. Cell life versus cell longevity: The mysteries surrounding the $\mathrm{NAD}(+)$ precursor nicotinamide. Curr Med Chem 2006; 13:883-95.

102. Balan V, Miller GS, Kaplun L, Balan K, Chong ZZ, Li F, et al. Life span extension and neuronal cell protection by Drosophila nicotinamidase. J Biol Chem 2008; 283:27810-9.

103. Chong ZZ, Maiese K. Enhanced tolerance against early and late apoptotic oxidative stress in mammalian neurons through nicotinamidase and sirtuin mediated pathways. Curr Neurovasc Res 2008; 5:159-70.

104. Jagani Z, Singh A, Khosravi-Far R. FoxO tumor suppressors and BCR-ABL-induced leukemia: a matter of evasion of apoptosis. Biochim Biophys Acta 2008; 1785:63-84.
105. Myatt SS, Lam EW. The emerging roles of forkhead box (Fox) proteins in cancer. Nat Rev Cancer 2007; 7:847-59.

106. van der Horst A, Burgering BM. Stressing the role of FoxO proteins in lifespan and disease. Nat Rev Mol Cell Biol 2007; 8:440-50.

107. Nemoto S, Fergusson MM, Finkel T. Nutrient availability regulates SIRT1 through a forkhead-dependent pathway. Science 2004; 306:2105-8

108. Motta MC, Divecha N, Lemieux M, Kamel C, Chen D, Gu W, et al. Mammalian SIRT1 represses forkhead transcription factors. Cell 2004; 116:551-63.

109. Kyoung Kim H, Kyoung Kim Y, Song IH, Baek SH, Lee SR, Hye Kim J, et al. Downregulation of a forkhead transcription factor, FOXO3a, accelerates cellular senescence in human dermal fibroblasts. J Gerontol A Biol Sci Med Sci 2005; 60:4-9.

110. Alcendor RR, Gao S, Zhai P, Zablocki D, Holle E, Yu X, et al. Sirt1 regulates aging and resistance to oxidative stress in the heart. Circ Res 2007; 100:1512-21.

111. Li M, Chiu JF, Mossman BT, Fukagawa NK. Downregulation of manganese-superoxide dismutase through phosphorylation of FOXO3a by Akt in explanted vascular smooth muscle cells from old rats. J Biol Chem 2006; 281:40429-39.

112. Miyauchi H, Minamino T, Tateno K, Kunieda T, Toko H, Komuro I. Akt negatively regulates the in vitro lifespan of human endothelial cells via a p53/p21-dependent pathway. EMBO J 2004; 23:212-20.

113. Kikuchi S, Nagai T, Kunitama M, Kirito K, Ozawa K, Komatsu N. Active FKHRL1 overcomes imatinib resistance in chronic myelogenous leukemia-derived cell lines via the production of tumor necrosis factor-related apoptosis-inducing ligand. Cancer Sci 2007; 98:1949-58.

114. Nowak K, Killmer K, Gessner C, Lutz W. E2F-1 regulates expression of FOXO1 and FOXO3a. Biochim Biophys Acta 2007; 1769:244-52

115. Bouchard C, Lee S, Paulus-Hock V, Loddenkemper C, Eilers M, Schmitt CA. FoxO transcription factors suppress Myc-driven lymphomagenesis via direct activation of Arf Genes Dev 2007; 21:2775-87.

116. Lynch RL, Konicek BW, McNulty AM, Hanna KR, Lewis JE, Neubauer BL, et al. The progression of $\mathrm{LNCaP}$ human prostate cancer cells to androgen independence involves decreased FOXO3a expression and reduced $\mathrm{p} 27^{\mathrm{KIP} 1}$ promoter transactivation. Mol Cancer Res 2005; 3:163-9.

117. Li Y, Wang Z, Kong D, Murthy S, Dou QP, Sheng S, et al. Regulation of FOXO3a/ beta-catenin/GSK-3beta signaling by 3,3'-diindolylmethane contributes to inhibition of cell proliferation and induction of apoptosis in prostate cancer cells. J Biol Chem 2007; 282:21542-50.

118. Cornforth AN, Davis JS, Khanifar E, Nastiuk KL, Krolewski JJ. FOXO3a mediates the androgen-dependent regulation of FLIP and contributes to TRAIL-induced apoptosis of LNCaP cells. Oncogene 2008; 27:4422-33.

119. Yang L, Xie S, Jamaluddin MS, Altuwaijri S, Ni J, Kim E, et al. Induction of androgen receptor expression by phosphatidylinositol 3-kinase/Akt downstream substrate, FOXO3a, and their roles in apoptosis of LNCaP prostate cancer cells. J Biol Chem 2005; 280:33558-65.

120. Liu P, Kao TP, Huang H. CDK1 promotes cell proliferation and survival via phosphorylation and inhibition of FOXO1 transcription factor. Oncogene 2008; 27:4733-44.

121. Kikuno N, Shiina H, Urakami S, Kawamoto K, Hirata H, Tanaka Y, et al. Knockdown of astrocyte-elevated gene-1 inhibits prostate cancer progression through upregulation of FOXO3a activity. Oncogene 2007; 26:7647-55.

122. Trotman LC, Alimonti A, Scaglioni PP, Koutcher JA, Cordon-Cardo C, Pandolfi PP. Identification of a tumour suppressor network opposing nuclear Akt function. Nature 2006; 441:523-7.

123. Jin GS, Kondo E, Miyake T, Shibata M, Takashima T, Liu YX, et al. Expression and intracellular localization of FKHRL1 in mammary gland neoplasms. Acta medica Okayama 2004; 58:197-205.

124. Hu MC, Lee DF, Xia W, Golfman LS, Ou-Yang F, Yang JY, et al. IkappaB kinase promotes tumorigenesis through inhibition of forkhead FOXO3a. Cell 2004; 117:225-37.

125. Sunters A, Madureira PA, Pomeranz KM, Aubert M, Brosens JJ, Cook SJ, et al. Paclitaxel-induced nuclear translocation of FOXO3a in breast cancer cells is mediated by c-Jun NH2-terminal kinase and Akt. Cancer Res 2006; 66:212-20.

126. Eddy SF, Kane SE, Sonenshein GE. Trastuzumab-resistant HER2-driven breast cancer cells are sensitive to epigallocatechin-3 gallate. Cancer Res 2007; 67:9018-23.

127. Zou Y, Tsai WB, Cheng CJ, Hsu C, Chung YM, Li PC, et al. Forkhead box transcription factor $\mathrm{FOXO} 3$ a suppresses estrogen-dependent breast cancer cell proliferation and tumorigenesis. Breast Cancer Res 2008; 10:21.

128. Paik JH, Kollipara R, Chu G, Ji H, Xiao Y, Ding Z, et al. FoxOs are lineage-restricted redundant tumor suppressors and regulate endothelial cell homeostasis. Cell 2007; 128:309-23.

129. Delpuech O, Griffiths B, East P, Essafi A, Lam EW, Burgering B, et al. Induction of Mxil-SR $\{\alpha\}$ by FOXO3a contributes to repression of Myc-dependent gene expression. Mol Cell Biol 2007; 27:4917-30.

130. Ticchioni M, Essafi M, Jeandel PY, Davi F, Cassuto JP, Deckert M, et al. Homeostatic chemokines increase survival of B-chronic lymphocytic leukemia cells through inactivation of transcription factor FOXO3a. Oncogene 2007; 26:7081-91.

131. Munoz-Fontela C, Marcos-Villar L, Gallego P, Arroyo J, Da Costa M, Pomeranz KM, et al. Latent protein LANA2 from Kaposi's sarcoma-associated herpesvirus interacts with 14-3-3 proteins and inhibits FOXO3a transcription factor. J Virol 2007; 81:1511-6. 


\section{A fork in the path: Developing therapeutic inroads with Fox0 proteins}

132. Hoekstra AV, Ward EC, Hardt JL, Lurain JR, Singh DK, Buttin BM, et al Chemosensitization of endometrial cancer cells through AKT inhibition involves FOXO1. Gynecol Oncol 2008; 108:609-18.

133. Maiese K, Chong ZZ, Shang YC, Hou J. Clever cancer strategies with FoxO transcription factors. Cell Cycle 2008; 7:3829-39.

134. Chong ZZ, Li F, Maiese K. Activating Akt and the brain's resources to drive cellular survival and prevent inflammatory injury. Histol Histopathol 2005; 20:299-315.

135. Anitha M, Gondha C, Sutliff R, Parsadanian A, Mwangi S, Sitaraman SV, et al. GDNF rescues hyperglycemia-induced diabetic enteric neuropathy through activation of the PI3K/Akt pathway. J Clin Invest 2006; 116:344-56.

136. Chong ZZ, Kang JQ, Maiese K. Erythropoietin is a novel vascular protectant through activation of Akt1 and mitochondrial modulation of cysteine proteases. Circulation 2002; 106:2973-9.

137. Chong ZZ, Li F, Maiese K. Erythropoietin requires NFKB and its nuclear translocation to prevent early and late apoptotic neuronal injury during beta-amyloid toxicity. Curr Neurovasc Res 2005; 2:387-99.

138. Kim KH, Oudit GY, Backx PH. Erythropoietin protects against doxorubicin-induced cardiomyopathy via a phosphatidylinositol 3-kinase-dependent pathway. J Pharmacol Exp Ther 2008; 324:160-9.

139. Tajes M, Yeste-Velasco M, Zhu X, Chou SP, Smith MA, Pallas M, et al. Activation of Akt by lithium: Pro-survival pathways in aging. Mech Ageing Dev 2009.

140. Chong ZZ, Kang JQ, Maiese K. Akt1 drives endothelial cell membrane asymmetry and microglial activation through Bcl-x(L) and caspase 1, 3 and 9. Exp Cell Res 2004; 296:196-207.

141. van der Heide LP, Jacobs FM, Burbach JP, Hoekman MF, Smidt MP. FoxO6 transcrip tional activity is regulated by Thr26 and Ser184, independent of nucleo-cytoplasmic shuttling. Biochem J 2005; 391:623-9.

142. Maiese K, Chong ZZ, Shang YC, Hou J. FoxO proteins: Cunning concepts and considerations for the cardiovascular system. Clin Sci (Lond) 2009; 116:191-203.

143. Maiese K, Chong ZZ, Li F. Driving cellular plasticity and survival through the signal transduction pathways of metabotropic glutamate receptors. Curr Neurovasc Res 2005 2:425-46.

144. Salvesen GS, Riedl SJ. Caspase mechanisms. Adv Exp Med Biol 2008; 615:13-23.

145. Chong ZZ, Kang JQ, Maiese K. Apaf-1, Bcl- - $\mathrm{x}_{\mathrm{L}}$, Cytochrome $c$ and Caspase-9 Form the Critical Elements for Cerebral Vascular Protection by Erythropoietin. J Cereb Blood Flow Metab 2003; 23:320-30.

146. Chong ZZ, Kang JQ, Maiese K. Essential cellular regulatory elements of oxidative stress in early and late phases of apoptosis in the central nervous system. Antioxid Redox Signal 2004; 6:277-87.

147. Shang YC, Chong ZZ, Hou J, Maiese K. The forkhead transcription factor FoxO3a controls microglial inflammatory activation and eventual apoptotic injury through caspase 3 . Curr Neurovasc Res 2009; 6:20-31.

148. Gomez-Gutierrez JG, Souza V, Hao HY, Montes de Oca-Luna R, Dong YB, Zhou HS, et al. Adenovirus-mediated gene transfer of FKHRL1 triple mutant efficiently induces apoptosis in melanoma cells. Cancer Biol Ther 2006; 5:875-83.

149. Matsuzaki H, Daitoku H, Hatta M, Tanaka K, Fukamizu A. Insulin-induced phosphorylation of FKHR (Foxo1) targets to proteasomal degradation. Proc Natl Acad Sci USA 2003; 100:11285-90.

150. Plas DR, Thompson CB. Akt activation promotes degradation of tuberin and FOXO3a via the proteasome. J Biol Chem 2003; 278:12361-6.

151. Leong ML, Maiyar AC, Kim B, O'Keeffe BA, Firestone GL. Expression of the serumand glucocorticoid-inducible protein kinase, Sgk, is a cell survival response to multiple types of environmental stress stimuli in mammary epithelial cells. J Biol Chem 2003 278:5871-82.

152. Lehtinen MK, Yuan Z, Boag PR, Yang Y, Villen J, Becker EB, et al. A conserved MSTFOXO signaling pathway mediates oxidative-stress responses and extends life span. Cell 2006; 125:987-1001

153. Song JJ, Lee YJ. Differential cleavage of Mst1 by caspase-7/-3 is responsible for TRAILinduced activation of the MAPK superfamily. Cell Signal 2008; 20:892-906.

154. Matsuzaki H, Daitoku H, Hatta M, Aoyama H, Yoshimochi K, Fukamizu A. Acetylation of Foxo1 alters its DNA-binding ability and sensitivity to phosphorylation. Proc Natl Acad Sci USA 2005; 102:11278-83.

155. Li F, Chong ZZ, Maiese K. Winding through the WNT pathway during cellular development and demise. Histol Histopathol 2006; 21:103-24.

156. Li F, Chong ZZ, Maiese K. Vital elements of the wnt-frizzled signaling pathway in the nervous system. Curr Neurovasc Res 2005; 2:331-40.

157. Smith WW, Norton DD, Gorospe M, Jiang H, Nemoto S, Holbrook NJ, et al Phosphorylation of p66Shc and forkhead proteins mediates Abeta toxicity. J Cell Biol 2005; 169:331-9.

158. Hoogeboom D, Essers MA, Polderman PE, Voets E, Smits LM, Burgering BM Interaction of FOXO with \{beta\}-Catenin Inhibits \{beta\}-Catenin/T Cell Factor Activity. J Biol Chem 2008; 283:9224-30.

159. Kerdiles YM, Beisner DR, Tinoco R, Dejean AS, Castrillon DH, DePinho RA, et al. Foxo1 links homing and survival of naive $\mathrm{T}$ cells by regulating L-selectin, CCR7 and interleukin 7 receptor. Nat Immunol 2009; 10:176-84.
160. Naito AT, Akazawa $H$, Takano $H$, Minamino $T$, Nagai $T$, Aburatani $H$, et al Phosphatidylinositol 3-kinase-Akt pathway plays a critical role in early cardiomyogenesis by regulating canonical Wnt signaling. Circ Res 2005; 97:144-51.

161. Emami KH, Corey E. When prostate cancer meets bone: Control by wnts. Cancer Lett 2007; 253:170-9.

162. Pohl BS, Knochel W. Overexpression of the transcriptional repressor FoxD3 prevents neural crest formation in Xenopus embryos. Mech Dev 2001; 103:93-106.

163. Perreault N, Sackett SD, Katz JP, Furth EE, Kaestner KH. Foxll is a mesenchyma Modifier of Min in carcinogenesis of stomach and colon. Genes Dev 2005; 19:311-5.

164. Balciunaite G, Keller MP, Balciunaite E, Piali L, Zuklys S, Mathieu YD, et al. Wn glycoproteins regulate the expression of FoxN1, the gene defective in nude mice. Nat Immunol 2002; 3:1102-8.

165. Ormestad M, Astorga J, Landgren H, Wang T, Johansson BR, Miura N, et al. Foxf1 and Foxf2 control murine gut development by limiting mesenchymal Wnt signaling and promoting extracellular matrix production. Development 2006; 133:833-43.

166. Kimura-Yoshida C, Tian E, Nakano H, Amazaki S, Shimokawa K, Rossant J, et al Crucial roles of Foxa2 in mouse anterior-posterior axis polarization via regulation of anterior visceral endoderm-specific genes. Proc Natl Acad Sci USA 2007; 104:5919-24.

167. Xu HT, Wei Q, Liu Y, Yang LH, Dai SD, Han Y, et al. Overexpression of axin downregulates TCF-4 and inhibits the development of lung cancer. Ann Surg Oncol 2007; 14:3251-9.

168. Kurayoshi M, Oue N, Yamamoto H, Kishida M, Inoue A, Asahara T, et al. Expression of Wnt-5a is correlated with aggressiveness of gastric cancer by stimulating cell migration and invasion. Cancer Res 2006; 66:10439-48.

169. Tomita H, Yamada Y, Oyama T, Hata K, Hirose Y, Hara A, et al. Development of gastric tumors in $\mathrm{Apc}(\mathrm{Min} /+)$ mice by the activation of the $\beta$-catenin/Tcf signaling pathway. Cancer Res 2007; 67:4079-87.

170. Ward EC, Hoekstra AV, Blok LJ, Hanifi-Moghaddam P, Lurain JR, Singh DK, et al The regulation and function of the forkhead transcription factor, Forkhead box O1, is dependent on the progesterone receptor in endometrial carcinoma. Endocrinology 2008; 149:1942-50

171. Hellwinkel OJ, Rogmann JP, Asong LE, Luebke AM, Eichelberg C, Ahyai S, et al. A comprehensive analysis of transcript signatures of the phosphatidylinositol-3 kinase/protein kinase B signal-transduction pathway in prostate cancer. BJU Int 2008; 101:1454-60.

172. Kim JH, Kim MK, Lee HE, Cho SJ, Cho YJ, Lee BL, et al. Constitutive phosphorylation of the FOXO1A transcription factor as a prognostic variable in gastric cancer. Mod Pathol 2007; 20:835-42.

173. Zethelius B, Berglund L, Sundstrom J, Ingelsson E, Basu S, Larsson A, et al. Use of multiple biomarkers to improve the prediction of death from cardiovascular causes. $\mathrm{N}$ Engl J Med 2008; 358:2107-16.

174. Brunet A, Sweeney LB, Sturgill JF, Chua KF, Greer PL, Lin Y, et al. Stress-dependent regulation of FOXO transcription factors by the SIRT1 deacetylase. Science 2004; 303:2011-5.

175. Bakker WJ, Harris IS, Mak TW. FOXO3a is activated in response to hypoxic stress and inhibits HIF1-induced apoptosis via regulation of CITED2. Mol Cell 2007; 28:941-53.

176. Han CY, Cho KB, Choi HS, Han HK, Kang KW. Role of FoxO1 activation in MDR expression in adriamycin-resistant breast cancer cells. Carcinogenesis 2008; 29:1837-44. 


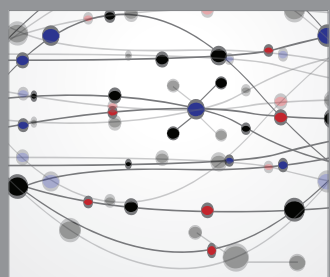

The Scientific World Journal
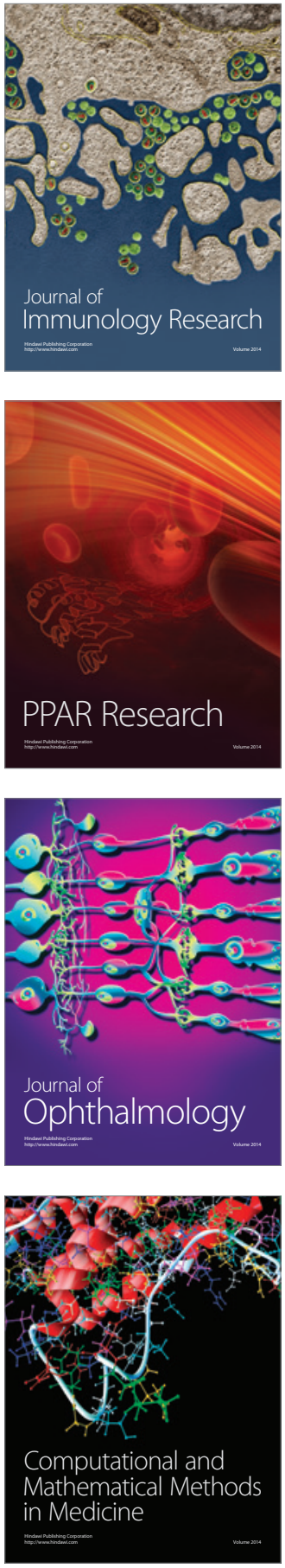

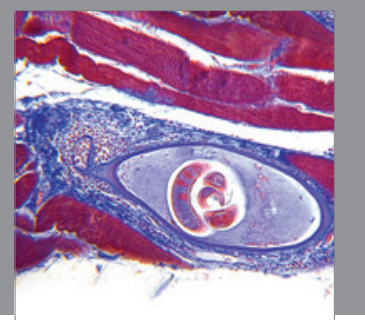

Gastroenterology

Research and Practice
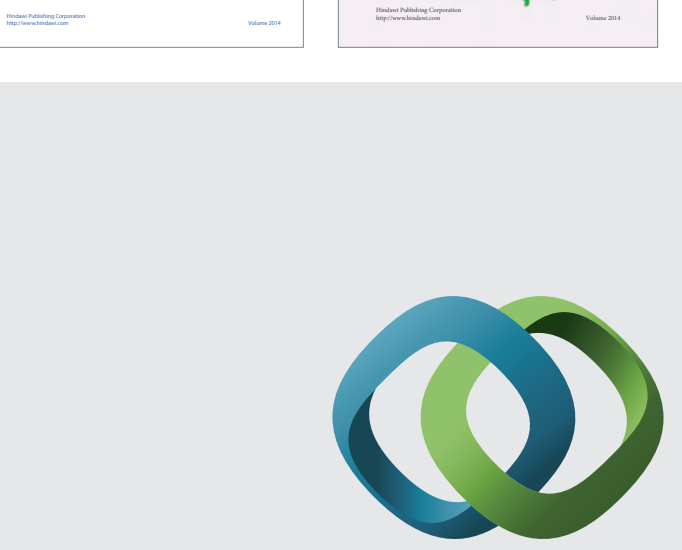

\section{Hindawi}

Submit your manuscripts at

http://www.hindawi.com
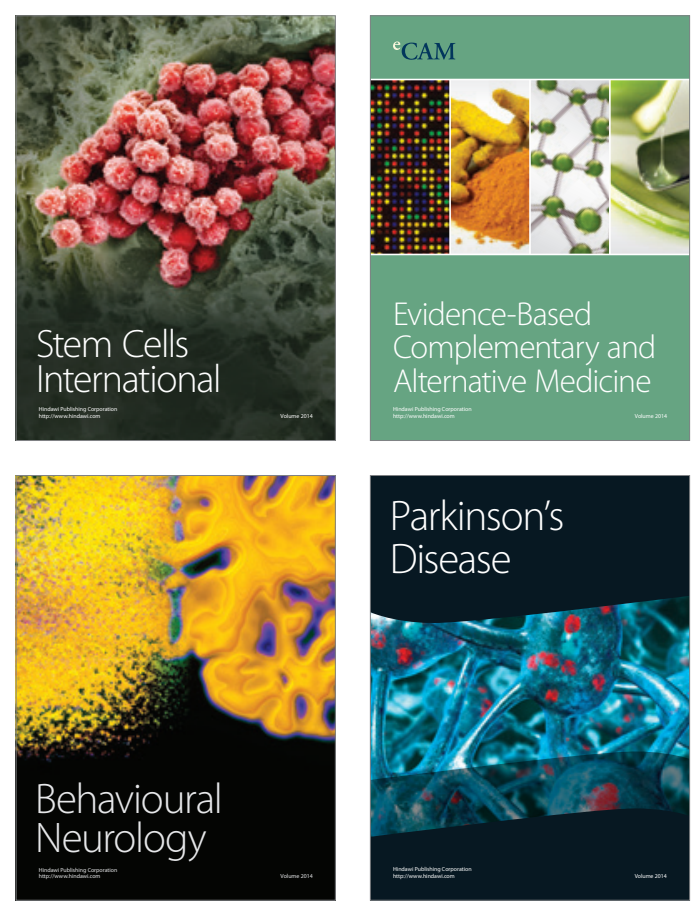

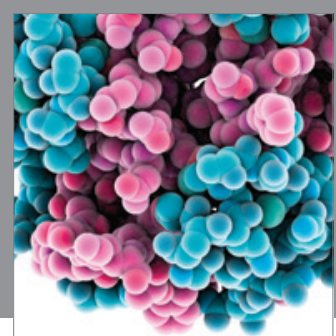

Journal of
Diabetes Research

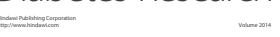

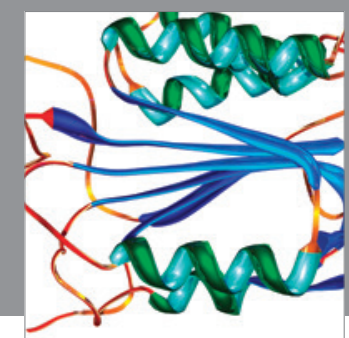

Disease Markers
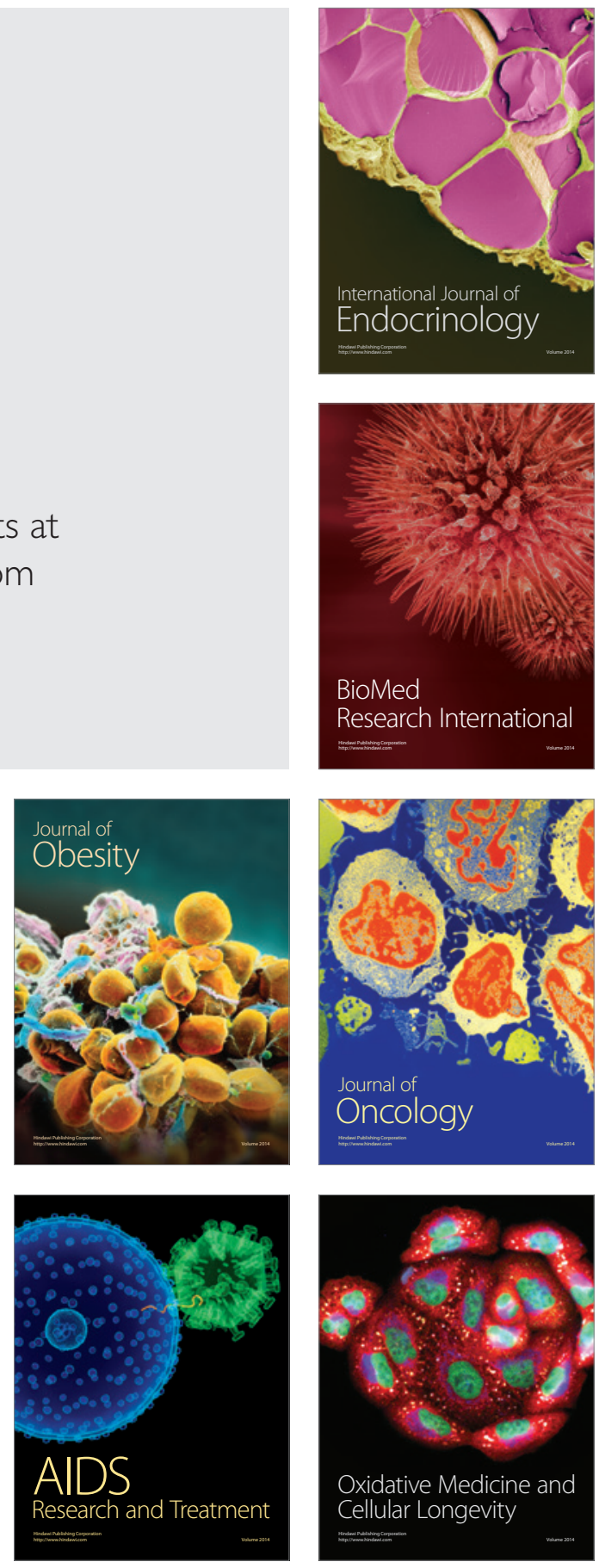